\title{
3
}

\section{THE RESULTS OF IMPLEMENTING SIMS IN ENGLISH SECONDARY SCHOOLS}

\author{
Adrie Visscher ${ }^{1}$, Phil Wild ${ }^{2}$ and Debbi Smith ${ }^{2}$ \\ ${ }^{1}$ Faculty of Educational Science \& Technology, University of Twente, The Netherlands \\ ${ }^{2}$ Department of Education, University of Loughborough, United Kingdom
}

Abstract: This paper describes an evaluative study of the implementation of the School Information Management System (SIMS) which is used to support management and administration in the majority of English secondary schools. There has been very little large-scale research on the use of computerised school information systems despite the massive growth since the early 1980s. The large-scale survey carried out for this study shows that SIMS use is particularly clerical and the use of SIMS to support school managers is still very limited. Problems identified include the reliability of SIMS, the degree of user training (especially managers), user support if problems occur, and the clarity of the innovation process. Relevant factors relating to the promotion of SIMS use are identified. Users are in general positive on the effects of SIMS use. It is concluded that wider and better SIMS use would be promoted by more carefully designed user training based on a thorough analysis of the needs of user groups.

Key words: School information system, usability, effectiveness, implementation

The original version of this chapter was revised: The copyright line was incorrect. This has been corrected. The Erratum to this chapter is available at DOI: 10.1007/978-0-387-35689-1_19 


\section{INTRODUCTION}

At two previous conferences of Working Group 3.7, the evaluation of the implementation of computerised school information systems (SISs) in Hong Kong and The Netherlands were presented. Here, we will present the results of similar research in England. The rationale for these studies was to fill the gap in our knowledge on this important type of computer use in schools, and, by that, to gain insight into the factors that prove to promote successful SISimplementation. In England SIMS (School Information Management System) has the largest market share of computerised school administration systems. SIMS is a modular but integrated system in that once entered, data is available between modules. Briefly, SIMS consists of about twenty modules that support the work of clerical staff and school managers and teachers (for details see Wild \& Walker 2001).

\section{RESEARCH QUESTIONS AND RESEARCH FRAMEWORK}

The following questions were addressed:

- The extent of, and ways in which SIMS was used in schools;

- The user opinion on the quality of SIMS;

- The nature and effects of the implementation process, and the characteristics of the schools into which SIMS was introduced;

- Factors affecting the degree of SIMS use.

The variables relating to the above issues that were investigated in this study fell into five distinct categories according to Visscher's model (see Figure 1), i.e., features of SIMS use, the implementation process, school organisation, and the intended/unintended effects. The study assumed possible interrelationships between all these variable groups. System use was expected to be more intense if users' evaluations of the qualities of the SIMS implementation process and the school organisation are more positive. More intense SIMS use was expected to lead to more intended and/or unintended effects. For an overview of the variables included in each block, the reader can refer to page 86 in Visscher et al., 2001. 


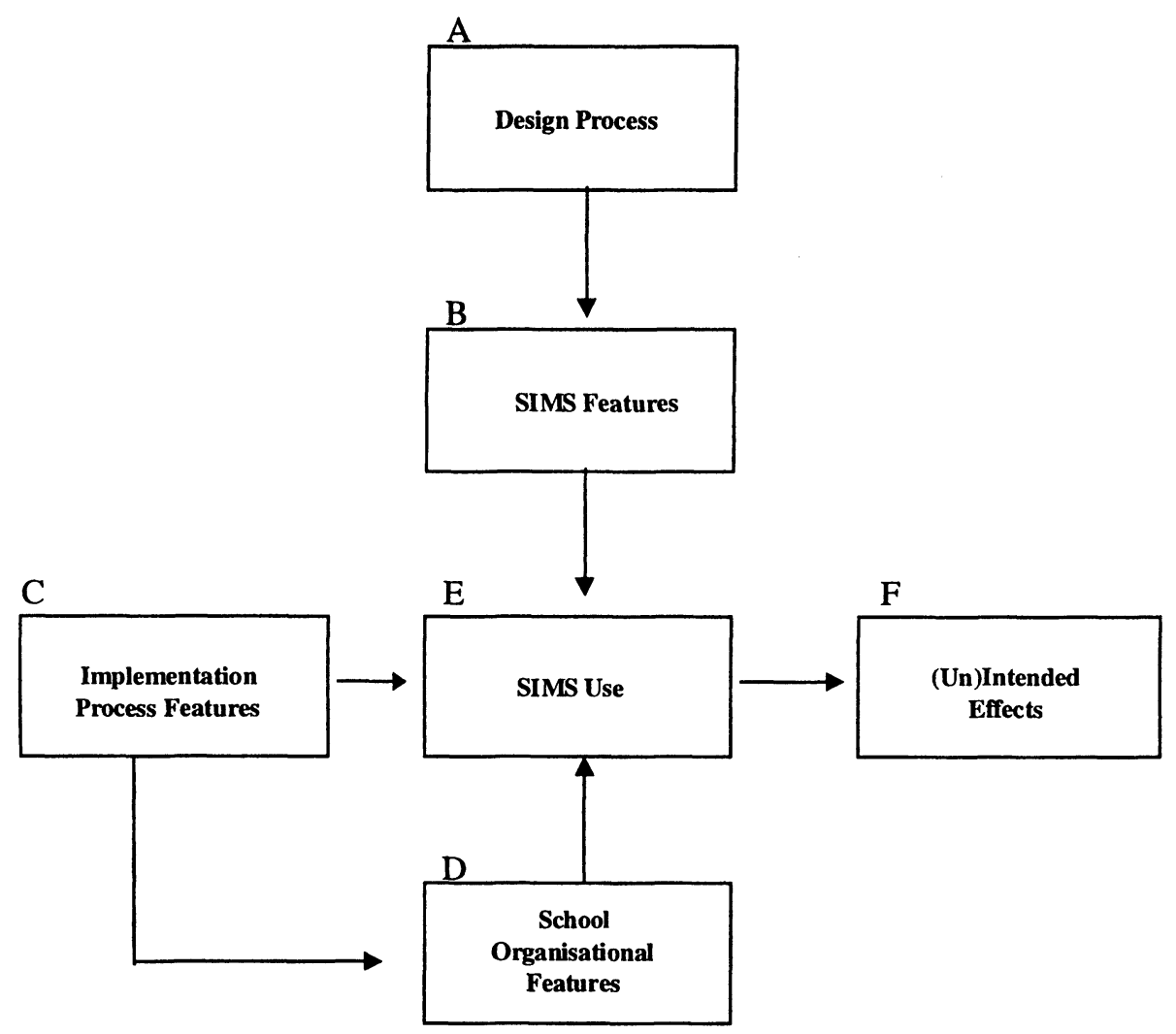

Figure 3-1. The variable groups influencing SIMS use and its effects (Visscher et al. 2001)

\section{METHOD AND DATA ANALYSIS}

A thousand sets of questionnaires were sent out to a selection of secondary schools in Local Education Authorities (LEAs), in the Midland Counties of England. The LEAs were chosen as they were known to support and promoted the use of SIMS. The schools represented about $25 \%$ of secondary schools in England. Each school was sent three questionnaires, which were to be completed separately by the principal, the SIMS system manager and a member of the clerical/administrative staff. The return rate after follow-up activities was $45 \%$.

Data analysis started with descriptive statistics with respect to all variables studied. Furthermore, to investigate to what extent variance in 
SIMS use can be explained by other variables in Figure 3-1, those variables that from a contents point of view were considered to be the most promising predictors of system use were entered into regression analyses. The number of available cases required a selection of potential predictors. The 13 selected variables cover aspects of the quality of SIMS (Block B Figure 3-1), features of the implementation process (Block C), and the characteristics of the schools in which SIMS has been implemented (Block D). Respondents' scores were transformed into normalized scores, allowing their mutual comparison, and thereafter entered into recoded pair-wise regression analyses on the use of SIMS by principals, clerks, and SIMS managers respectively. Regression analyses were also carried out on SIMS use at the whole school level (a school use score was defined as the sum of the extent of SIMS use by the principal, clerk, and SIMS manager of that school).

\section{RESULTS}

Non-response analysis indicated that the schools in the response group represent the population of SIMS schools quite well with respect to a number of crucial variables like the length and intensity of SIMS use, the nature of the experience of the implementation process, and the impact of SIMS use.

\subsection{Degree of use of SIMS}

Table 3-1 shows the percentage of staff who used the data directly or indirectly (i.e., used data from the system provided by someone else) estimated within time blocks of time per week. There were some aspects of the results, which were within expectation. For example, clerical staff used SIMS for long periods of time directly for the inputting and updating of data, but a large proportion of them did not use the data indirectly. The results from management staff indicated that they used SIMS for short periods both directly and indirectly. Both the SIMS manager and clerical staff used SIMS directly far more than management staff. Perhaps significant was the very little time that school managers used the system directly, indicating only cursory use of management decision support functions. 
Table 3-1. Direct and Indirect use of SIMS

\begin{tabular}{|c|c|c|c|c|c|c|}
\hline & \multicolumn{2}{|c|}{ Management } & \multicolumn{2}{|c|}{ SIMS manager } & \multicolumn{2}{|c|}{ Clerical } \\
\hline $\begin{array}{l}\text { Hours } \\
\text { per week }\end{array}$ & $\begin{array}{c}\text { Direct use } \\
\%\end{array}$ & $\begin{array}{c}\text { Indirect } \\
\text { use } \\
\% \\
\end{array}$ & $\begin{array}{c}\text { Direct use } \\
\%\end{array}$ & $\begin{array}{c}\text { Indirect } \\
\text { use } \\
\%\end{array}$ & $\begin{array}{c}\text { Direct use } \\
\%\end{array}$ & $\begin{array}{c}\text { Indirect } \\
\text { use } \\
\% \\
\end{array}$ \\
\hline$<1$ & 36 & 35 & 10 & 43 & 4 & 57 \\
\hline $1-4$ & 38 & 46 & 27 & 37 & 7 & 21 \\
\hline $5-10$ & 19 & 17 & 21 & 9 & 14 & 13 \\
\hline $11-20$ & 6 & 2 & 25 & 4 & 29 & 3 \\
\hline $21-30$ & 1 & 1 & 13 & 4 & 25 & 3 \\
\hline$>30$ & 0 & 1 & 4 & 3 & 21 & 3 \\
\hline n & 205 & 205 & 75 & 75 & 309 & 309 \\
\hline
\end{tabular}

Part of the questionnaire was aimed exclusively at principals to obtain some measure of how much SIMS was being used to support management decision-making processes. The principals were asked to indicate whether they used certain modules, which were judged to be able to provide relevant management focussed information. The results are summarised in Table 32.

Table 3-2. Use to support Management Decisions in percentages of users $(\mathrm{n}=58)$

\begin{tabular}{lccc}
\hline Modules in SIMS & \% Use & \% Don't use & \% Don't know \\
\hline Analyst & 2 & 78 & 21 \\
Assessment & 38 & 50 & 12 \\
Attendance & 66 & 29 & 5 \\
Cover & 41 & 53 & 5 \\
Curriculum & 24 & 64 & 12 \\
Equipment & 12 & 72 & 16 \\
Exams & 66 & 26 & 8 \\
Financial management & 78 & 16 & 6 \\
system & & & \\
Key Stage & 19 & 66 & 16 \\
Midas & 74 & 19 & 7 \\
Options & 28 & 62 & 10 \\
Performance Indicator & 16 & 69 & 16 \\
Personnel & 67 & 24 & 8 \\
Report Generator & 52 & 38 & 10 \\
SENCO & 22 & 62 & 15 \\
STAR & 74 & 21 & 5 \\
Timetable & 71 & 24 & 5 \\
Value added & 9 & 79 & 12 \\
\hline
\end{tabular}

Some of the modules were, at the time of the survey, recent additions aimed at providing target setting information for school improvement. Two of these, Performance Indicator and Value Added, which would be used for 
setting improvement targets as required by Central Government, were showing little use. However, there was some indication that some schools used proprietary spreadsheets in preference to the SIMS software modules to make the required returns to LEAs. The overall conclusion is that SIMS is under-utilised considerably as a management tool.

\subsection{Perceived quality of SIMS}

The second research question concerned the quality of SIMS as perceived by its users. Table 3-3 shows the response to the question "Does the system always work?"

Table 3.33. . Does the system always work?

\begin{tabular}{lcccc}
\hline & $\begin{array}{c}\text { Management \% } \\
(\mathrm{n}=205)\end{array}$ & $\begin{array}{c}\text { SIMS manager \% } \\
(\mathrm{n}=75)\end{array}$ & $\begin{array}{c}\text { Clerical \% } \\
(\mathrm{n}=309)\end{array}$ & $\begin{array}{c}\text { Total \% } \\
(\mathrm{n}=589)\end{array}$ \\
\hline No & 9 & 12 & 10 & 10 \\
Usually & 52 & 60 & 74 & 65 \\
Yes & 12 & 15 & 13 & 13 \\
No response & 27 & 13 & 3 & 13 \\
\hline
\end{tabular}

The results (only $13 \%$ of users experience that SIMS always works!) did not show a resounding confidence in the system overall which in itself could be limiting its greater integration into the administration and management of schools.

Further questions showed that:

- $81 \%$ were positive about data accuracy and only $3 \%$ are negative;

- $77 \%$ were positive about data currency and only $4 \%$ are negative;

- $64 \%$ were positive about data completeness and only $8 \%$ are negative;

- $54 \%$ were positive about the ease of retrieving data and $9 \%$ negative;

- $51 \%$ were positive about the data entry screen format and $7 \%$ negative;

- $40 \%$ were positive about the data entry system terms with $12 \%$ negative;

- $57 \%$ were positive about the keyboard entry of data with $8 \%$ negative;

- $53 \%$ were positive about the predefined printouts with $6 \%$ negative;

- $38 \%$ were positive about the user-defined printouts with $18 \%$ negative.

When asked to compare aspects of the SIMS system with previous systems, such as data accuracy, relevance, currency and completeness around $60 \%$ of respondents were positive, with only 5\% responding negatively. However, only $62 \%$ were positive when comparing the availability of data with previous systems, with $6 \%$ negative and $13 \%$ neutral.

Results concerning school management showed that $66 \%$ were positive about the way SIMS supported management with $27 \%$ being neutral and $8 \%$ being negative. When asked to compare management support afforded by 
SIMS with previous systems $64 \%$ were positive, $11 \%$ were neutral and $4 \%$ negative (21\% don't know).

\subsection{The process of implementation}

Research question three referred to the features of the implementation process by which SIMS had been introduced into UK schools, the organisational features of those schools, and the effects of implementing SIMS. Table 3-4 shows the total number of hours training from both external and internal sources.

Table 3-4. Hours of external and internal training in percentages

\begin{tabular}{lccc}
\hline External hours & Management $(\mathrm{n}=160)$ & SIMS Manager $(\mathrm{n}=73)$ & Clerical $(\mathrm{n}=302)$ \\
$<1$ & 24 & 4 & 5 \\
$1-4$ & 19 & 15 & 9 \\
$5-10$ & 17 & 18 & 21 \\
$11-20$ & 20 & 16 & 18 \\
$21-30$ & 6 & 12 & 19 \\
$>30$ & 15 & 34 & 28 \\
\hline Internal hours & Management $(\mathrm{n}=160)$ & SIMS Manager $(\mathrm{n}=71)$ & Clerical $(\mathrm{n}=297)$ \\
$<1$ & 48 & 73 & 52 \\
$1-4$ & 36 & 14 & 27 \\
$5-10$ & 11 & 4 & 12 \\
$11-20$ & 3 & 6 & 3 \\
$21-30$ & 2 & 1 & 2 \\
$>30$ & 0 & 1 & 4 \\
\hline
\end{tabular}

A large proportion of SIMS managers and clerical staff had undergone some external training in using the SIMS system, many reporting 5-10 hours or more. This represented a considerable expense to schools. However, the results for school managers, with $43 \%$ reporting up to four hours external training and $84 \%$ reporting up to four hours internal training, together with about forty nil responses for this group, suggests that investment in the use of the system to support management processes was rather low.

Overall, the responses showed that about $20 \%$ of respondents were unhappy or even very unhappy with the quantity of external training, although for the managers this was $25 \%$. Only $8 \%$ reported that they were (very) unhappy with the quality of this training but for the managers this was fourteen percent.

Thirty percent of the managers and thirty-eight percent of SIMS managers were (very) unhappy with the quantity of internal training although only $9 \%$ of managers were unhappy with the quality of internal training. However, $27 \%$ of SIMS managers were (very) unhappy with the quality of internal training. 
An important aspect of implementation was the availability of help for users when things go wrong. Thirty-two percent reported that it was (very) hard to get help from outside school and $27 \%$ reported that it was (very) hard to get help from inside school. Overall, $85 \%$ of the users tended to solve problems by themselves without recourse to outside or internal support. However, $41 \%$ reported that they often used the LEA (SIMS Office) hotline and 39\% used colleagues within school to help. The user manual was only used on a regular basis by $21 \%$ of staff and the on-screen help by only $17 \%$ of staff. According to $60 \%$ of users, the overall pace of introduction was regarded about right with $20 \%$ reporting on each side of this middle line.

\subsection{School organisational features}

The majority of staff (59\%) felt that the goals of introducing SIMS were clear or very clear with $14 \%$ being less than neutral on this issue. However, there was less clarity on the means by which SIMS was introduced to meet the goals with only $44 \%$ indicating better than neutral. Ninety-three percent of staff reported that they felt some (or better) encouragement to use SIMS from both the school co-ordinator of the SIMS implementation and the schools' senior management team was needed. At the time of the survey, 74\% of the responses indicated a positive motivation towards using SIMS with only $5 \%$ being unmotivated. When asked about their feelings if SIMS were to be withdrawn, $86 \%$ said that they would be (very) unhappy, with a further $11 \%$ being neutral, and only $3 \%$ would be happy.

\subsection{Effects of SIMS use}

The introduction of SIMS into schools had generated several effects in the perception of SIMS users. Table 3-5 presents some of them and it can be seen that higher percentages for all listed effects are found on the positive side. The table shows a rank order of positive effects, starting with $60 \%$ of users indicating that the evaluation of school performance had improved due to SIMS, then came the utilisation of school resources (50\%), information for curriculum planning (40\%), school internal communication (31\%), workload (30\%) and finally the positive impact on stress (23\%). About a quarter of the respondents thought that using SIMS had increased both their workload and stress. 
Table 3-5. School Level Effects of the Use of SIMS in Numbers and Percentages $(n=283)$

\begin{tabular}{|c|c|c|c|c|c|c|}
\hline & \multicolumn{2}{|c|}{ Negative } & \multicolumn{3}{|c|}{ Positive } & \multirow[b]{2}{*}{$\begin{array}{c}\% \text { of } \\
\text { positive } \\
\text { responses }\end{array}$} \\
\hline & $\begin{array}{l}\text { Much } \\
\text { worse }\end{array}$ & Worse & $\begin{array}{l}\% \text { of } \\
\text { negative } \\
\text { responses }\end{array}$ & Better & $\begin{array}{l}\text { Much } \\
\text { better }\end{array}$ & \\
\hline $\begin{array}{l}\text { Evaluation of school } \\
\text { performance }\end{array}$ & 1 & 4 & 1 & 122 & 47 & 60 \\
\hline $\begin{array}{l}\text { Utilisation of school } \\
\text { resources }\end{array}$ & 4 & 7 & 3 & 103 & 37 & 50 \\
\hline $\begin{array}{l}\text { Information for } \\
\text { curriculum planning }\end{array}$ & 1 & 9 & 3 & 73 & 38 & 40 \\
\hline $\begin{array}{l}\text { Internal } \\
\text { communication with } \\
\text { colleagues }\end{array}$ & 6 & 16 & 8 & 63 & 23 & 31 \\
\hline Workload & 15 & 52 & 23 & 63 & 23 & 30 \\
\hline Stress & 17 & 48 & 23 & 50 & 15 & 23 \\
\hline
\end{tabular}

Note: the table does not contain the percentages for the "same" response category. The difference between $100 \%$ and the sum of the percentages for the positive and the negative answers concerns the percentage of respondents who neither observed an improvement nor deterioration.

\subsection{Factors related to the extent of SIMS use}

The fourth research question focused on the factors that had a relationship with the degree of SIMS usage. To investigate the extent to which variance in the degree of SIMS use is explained by (some of) the variables in Figure 3-1, those which the researchers considered to be the most promising predictors of SIMS use were entered into regression analyses on direct and indirect SIMS use at the level of the principal, SIMS administrator, and clerk; and at the whole school level.

Six of the 13 entered variables explained variance in SIMS use indices: motivation for using SIMS at the start of its introduction, computer experience, the amount of external training, and the amount of internal training, users' judgement of the quality of the information that could be retrieved from SIMS, and the length of time using SIMS.

The other seven variables did not explain any further variance additional to the six variables in Table 3-6. These seven variables are: ease of external help in case of problems with SIMS, ease of school internal help, encouragement to use SIMS from the principal, encouragement from the SIMS manager, satisfaction with external training, the clarity of the goals of introducing SIMS into schools, and finally the clarity of the means to accomplish these goals. 
Table 3-6. Results of Regression Analysis on SIMS use

\begin{tabular}{|c|c|c|c|c|c|c|c|}
\hline \multirow{2}{*}{ Variable } & \multirow[b]{2}{*}{$\begin{array}{c}\text { Coeffic- } \\
\text { ients }\end{array}$} & \multicolumn{3}{|c|}{ Direct use } & \multicolumn{3}{|c|}{ Indirect use } \\
\hline & & Clerks & $\begin{array}{c}\text { Manage- } \\
\text { ment }\end{array}$ & $\begin{array}{l}\text { Whole } \\
\text { school }\end{array}$ & Clerks & $\begin{array}{c}\text { Manage- } \\
\text { ment }\end{array}$ & $\begin{array}{l}\text { Whole } \\
\text { school }\end{array}$ \\
\hline \multirow{3}{*}{$\begin{array}{l}\text { 1. Start- } \\
\text { motivation }\end{array}$} & Beta* & & & & 4.30 & & \\
\hline & Bstand* & & & & 0.14 & & \\
\hline & Sign.* & & & & 0.05 & & \\
\hline \multirow{3}{*}{$\begin{array}{l}\text { 2. Computer } \\
\text { experience }\end{array}$} & Beta & & 0.80 & & & & \\
\hline & Bstand & & 0.20 & & & & \\
\hline & Sign. & & 0.02 & & & & \\
\hline \multirow{3}{*}{$\begin{array}{l}\text { 3. External } \\
\text { training }\end{array}$} & Beta & 1.60 & 1.1 & 1.40 & & 0.61 & \\
\hline & Bstand & 0.22 & 0.40 & 0.23 & & 0.21 & \\
\hline & Sign. & 0.00 & 0.00 & 0.00 & & 0.02 & \\
\hline \multirow{3}{*}{$\begin{array}{l}\text { 4. Internal } \\
\text { training }\end{array}$} & Beta & & & & & 1.70 & \\
\hline & Bstand & & & & & 0.29 & \\
\hline & Sign. & & & & & 0.00 & \\
\hline \multirow{3}{*}{$\begin{array}{l}\text { 5. Information } \\
\text { quality }\end{array}$} & Beta & & & 0.80 & & & \\
\hline & Bstand & & & 0.22 & & & \\
\hline & Sign. & & & 0.00 & & & \\
\hline \multirow{4}{*}{$\begin{array}{l}\text { 6. Length } \\
\text { personal use }\end{array}$} & Beta & & & & & & 0.30 \\
\hline & Bstand & & & & & & 0.15 \\
\hline & Sign. & & & & & & 0.02 \\
\hline & R square & .05 & .20 & .11 & .02 & .11 & .02 \\
\hline
\end{tabular}

${ }^{*}$ Beta $=$ unstandardised Beta; Bstand = standardised Beta; signif. = level of significance

The other seven variables did not explain any further variance additional to the six variables in Table 3-6. These seven variables are: ease of external help in case of problems with SIMS, ease of school internal help, encouragement to use SIMS from the principal, encouragement from the SIMS manager, satisfaction with external training, the clarity of the goals of introducing SIMS into schools, and finally the clarity of the means to accomplish these goals.

- Five percent of variance in the degree of direct SIMS use by clerks is explained by variation in external training; for indirect clerical use 'start motivation' explains 2 percent of the variance.

- Twenty percent of the differences in the extent of managers' direct SIMS use are explained by variance in the variables 'computer experience' and 'external training'; indirect managerial SIMS use is explained for eleven percent by variation in internal and external training.

- At whole school level (the sum of SIMS use for all three types of SIMS users in schools) 'external training' and 'quality of SIMS information' as perceived by users explain eleven percent of the variation in direct use; the length system use seems to matter for indirect use (2\% explained variance). 
Overall, 'external training' proved to be the most powerful explanation of variation in SIMS use as it explains variance in two SIMS use indices. The other five variables in Table 6 account for variation in one of five different SIMS use indices.

\section{CONCLUSION AND DISCUSSION}

This evaluation of the introduction of SIMS shows that at the time of this evaluation study, i.e., after about a decade of design and implementation activities, full SIMS implementation had not been accomplished. In other words, even in LEAs where SIMS was promoted, schools do not benefit as much as they could from all the twenty integrated SIMS modules that offer relevant support to school staff.

The descriptive results show that use in general was particularly of the direct, clerical kind. Managerial and indirect use of SIMS are in other words limited. Interestingly and perhaps contrary to expectation, if SIMS was used by managers it was mainly used directly. Quite a few of the SIMS modules proved to be used intensively while others that seem just as important for running schools well were found to be little used (e.g., Attendance, Curriculum planner, Analyst, Alert, Financial Management).

Given the trend of decentralisation towards schools (school-based management) which implies that school policy-making has and will become much more relevant, than when Central Government took most decisions for schools, the search for ways to promote SIS-informed school policy-making is urgently needed. The findings in this study strongly indicate that the extent of SIMS use has relationships with the other blocks in Figure 1. As far as the quality of SIMS (Block B) is concerned there were user criticisms concerning some of the SIMS features. For example, only two-third of the respondents stated that SIMS usually works when they wanted to use it. However, a few respondents were (very) negative about most of the SIMS characteristics investigated. Dissatisfaction with the quality of SIMS possibly is due to the strategy used for the design and development of SIMS (Block A in Figure 3-1; cf. Visscher, Wild \& Fung 2001).

Similarly, regarding the process of implementing SIMS (Block C) there is also some room for improvement. User training for about two-third of all respondents were found to be external training delivered for about 1-30 hours to clerical staff and SIMS administrators; thus managers had received little training. A considerable number of respondents (about 25\%) seemed unhappy about the training they had received.

When experiencing problems with SIMS, user support both internal as well as external to schools is hard to get for about one-third of all 
respondents. Most users seemed to try to solve the problems by themselves; about $40 \%$ of them received support from other sources (the SIMS hotline, colleagues).

As far as the characteristics of the schools in which SIMS was introduced, the goals of the SIMS innovation was clear to $60 \%$ of school staff, whereas the means for accomplishing these goals seem less clear (clear only to $44 \%$ of respondents). Almost all respondents felt encouraged by their school managers and school internal SIMS managers, and also were quite motivated to use the SIMS package.

With respect to the effects of the introduction of SIMS, the respondents were overall (very) positive regarding all effects studied.

Start motivation, previous computer knowledge, the amount of external and internal training, the perceived quality of the information that SIMS provided, and the length of personal SIMS use explain considerable amounts of variance in one or more of the SIMS use indices. Because these six predictors proved to be critical success factors, they require careful attention in the design of computerised school information systems and in the strategies for implementing them successfully.

The magnitude of external training, especially, proved to be a powerful explanation of differences between respondents in their use of SIMS. The influence of the extent and quality of user training in our view has not been recognized enough, even though these aspects have been prevalent issues in the introduction of IT systems in industry and commerce. In general, the amount of user training should be increased and we need to find out what types of training would produce the best results for the target group. The target group includes adults with considerable work experience at clerical and/or managerial level in schools and the training content should match those features in order to be successful. Careful user training has also much relevance for some of the other predictors of SIMS use (see Table 3-6), as high quality training can fulfil an important role in motivating users for SIS use, by clarifying where and how the SIS can help and add value to their duties. It can also provide the target group with the expertise and skills for SIS use, and show users alternative problem solving strategies they can follow, if SIMS does not do what they want it to do.

Via (quasi-)experimental research designs, alternative strategies for user training must be tested as to their effectiveness. Thus, our knowledge in this area can be refined, the full utilisation of the potential of computerised school information systems increased, and the functioning of schools improved. 


\section{REFERENCES}

Visscher, A.J., Wild, P. \& Fung, A.C.W. (Eds.) (2001). Information Technology in Educational Management; Synthesis of experience, research and future perspectives on computer-assisted school information systems. Kluwer Academic Publishers, Dordrecht/Boston/London.

Wild, P. \& Walker, J. (2001). The Commercially Developed SIMS from a Humble Beginning. In Information Technology in Educational Management; Synthesis of experience, research and future perspectives on computer-assisted school information systems, Visscher, A.J., Wild, P. \& Fung, A.C.W. (eds.).. Kluwer, Dordrecht/Boston/London. 